\title{
A case report of renal vein thrombosis following whiplash by husband with review article
}

\author{
Telma Zahirian Moghadam ${ }^{\circledR}$, Hamed Mohseni Rad ${ }^{2 *}$ \\ ${ }^{1}$ Social Determinants of Health Research Center, Ardabil University of Medical Sciences, Ardabil, Iran \\ ${ }^{2}$ Department of Surgery, School of Medicine and Allied Medical Sciences, Imam Reza Hospital, Ardabil University of Medical Sciences, \\ Ardabil, Iran
}

\section{A R T I C L E IN F O}

Article Type:

Case Report

\section{Article History:}

Received: 7 August 2019

Accepted: 3 October 2019

Published online: 21 October 2019

\section{Keywords:}

Renal vein thrombosis

Injury

Kidney

\begin{abstract}
A B S T R A C T
Renal vessel thrombosis results in kidney loss unless be re-vascularized immediately. We report a case of right renal vein thrombosis in a 43 years old woman following whiplash trauma by her husband without any associated parenchymal or arterial injury. She presented to our emergency center with right flank pain for three days. She reported whiplashing by her husband 3 days before admission. Abdominopelvic spiral computerized tomography (CT) with intra-venous contrast showed a non-enhancement, enlargement and peri-renal fat-stranding in the right kidney. With the diagnosis of renal vein thrombosis following whiplash, the patient was heparinized 5000 IU sub-cutaneous every 8 hours and discharged with warfarin after resolution of gross hematuria. Follow-up with nuclear scan 10 weeks later showed the right kidney is non-function.
\end{abstract}

Implication for health policy/practice/research/medical education:

Renal vein thrombosis may happen following blunt flank trauma especially in females with low peri- renal fat support.

Please cite this paper as: Zahirian Moghadam T, Mohseni Rad H. A case report of renal vein thrombosis following whiplash by husband with review article. J Renal Inj Prev. 2020; 9(1): e07. DOI: 10.15171/jrip.2020.07.

\section{Introduction}

Renal vessel thrombosis leads to kidney loss unless be revascularized immediately. Renal pedicle injury usually could not be repaired because of delayed diagnosis and associated major visceral insults. Previously, pedicle injury was accompanied by $50 \%$ mortality rate because of associated injuries (1).

\section{Case Presentation}

We report a case of right renal vein thrombosis in a 43 years old woman following whiplash trauma by her husband without any associated parenchymal or arterial injury.

She presented to our emergency center with right flank pain which was lasted for three-day. She reported whiplashing by her husband three days before the admission. Her sore relieved by painkillers, however nausea exacerbated progressively. At presentation she was stable clinically and serum creatinine was $1.3 \mathrm{mg} / \mathrm{dL}$ with gross hematuria.

Abdominopelvic spiral computerized tomography
(CT) with intra-venous contrast (Figure 1) showed nonenhancement of right kidney with enlargement and perirenal fat stranding. Some enhancement in renal artery was seen too but no dye in the parenchyma was detected.

With the diagnosis of renal vein thrombosis following whiplash, the patient was heparinized 5000 IU subcutaneous every 8 hours and discharged with warfarin after resolution of gross hematuria. Follow-up with nuclear scan 10 weeks later showed the right kidney is non-function (Figure 2).

\section{Discussion}

Renal vein thrombosis following blunt trauma is seldom reported $(2,3)$. Renal vein thrombosis is usually neglected probably because of lack of suspicion, ignored clinical manifestation and not performance of useful imaging (4). Renal vein thrombosis may resolve spontaneously or cause renal failure or hypertension (5). Virchow's Triad explains that endothelial damage (like blunt trauma), stasis of blood flow and hypercoagulability are risk factors for venous thrombosis (6). Hematuria, proteinuria and 


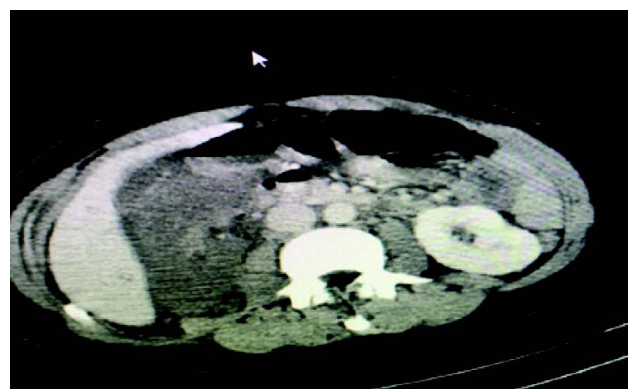

Figure 1. Abdominal CT with IV contrast that shows no enhancement in right kidney.

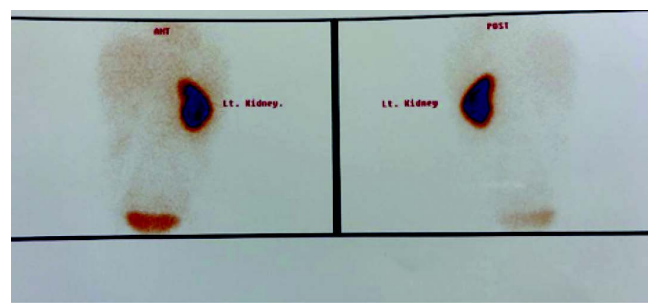

Figure 2. Dimercaptosuccinic acid (DMSA) scan 10-week after trauma that shows no uptake in right kidney.

worsening of renal function beside nausea, vomiting, fever, flank pain and tenderness and enlarged kidney are renal vein thrombosis manifestations. Although in our case renal vein thrombosis was in the right side, left renal vein thrombosis occurs more common and may cause left gonadal vein involvement and pelvic congestion syndrome in females or left varicocele in males (7).

Following renal vein thrombosis, the kidney becomes larger and reaches its maximum size during a week. Then it gets atrophied during following weeks. In $90 \%$ of cases in acute phase of thrombosis, ultra-sonography shows kidney enlargement and hyper-echogenicity (8). Doppler ultrasonography is also suitable for screening. Intravenous CT shows diminished or absent opacification of collecting ducts and/or prolonged corticomedullary differentiation (9).

Magnetic resonance angiography is less invasive and less nephrotoxic. Subcapsular contrast enhancement could be affirmative for renal vein thrombosis. Accordingly, nuclear scintigraphy may illustrate delayed washing of tracer.

Management of renal vein thrombosis changed from surgical to medical therapy with intra-venous then oral anticoagulation. However thrombectomy/thrombolysis procedures should be applied in bilateral thrombosis, pulmonary embolism, renal transplant and inferior vena cava extension of thrombus (10). Renal vein anastomosis to inferior mesenteric vein has been reported (11). On the other hand, nephrectomy may be considered in ruptured allograft or impending to rupture of necrotic kidney (12). Sepsis, hemorrhage and recurrent thromboembolism could lead to high mortality. Baseline and other kidney functions have a good prognostic factor (13).

\section{Conclusion}

Renal vein thrombosis may happen following blunt flank trauma especially in females with low peri-renal fat support and should be in mind in management of these patients to do rapid and effective treatment.

\section{Authors' contribution}

HMR and TZM designed the study, observed accuracy and validity of the study. HMR collected the data. HMR and TZM supervised the project. H HMR and TZM wrote the paper. All authors edited and revised the final manuscript and accepted its publication.

\section{Conflicts of interest}

There are no competing interests to declare.

Ethical considerations

Ethical issues including plagiarism, double publication, and redundancy have been completely observed by the authors. Informed consent was obtained from the patient for the publication of this report.

\section{Funding/Support}

We do not have any financial support.

\section{References}

1. Sturm JT, Perry JF Jr, Cass AS. Renal artery and vein injury following blunt trauma. Ann Surg. 1975;182:696. doi: 10.1097/00000658-197512000-00006.

2. Kau E, Patel R, Shah O. Isolated renal vein thrombosis after blunt trauma. Urology. 2004;64:807-8. doi: 10.1016/j. urology.2004.05.043.

3. Berkovich GY, Ramchandani P, Preate DL Jr, Rovner ES, Shapiro MB, Banner MP. Renal vein thrombosis after martial arts trauma. J Trauma. 2001;50:144-5. doi: 10.1097/00005373-200101000-00030.

4. Asghar M, Ahmed K, Shah S, Siddique M, Dasgupta P, Khan M. Renal vein thrombosis. European J Vascular Endovascular Surg. 2007;34:217-23. doi: 10.1016/j. ejvs.2007.02.017.

5. Tektonidou MG . Renal involvement in the antiphospholipid syndrome (APS) - APS nephropathy. Clin Rev Allergy Immunol. 2009;36:131-40. doi: 10.1007/s12016-0088112-z.

6. Beard JD, Gaines PA, Loftus I. Vascular and Endovascular Surgery E-Book: Companion to Specialist Surgical Practice. Elsevier Health Sciences; 2013.

7. Wang IK, Lee CH, Yang BY, Chang HY, Lin CL, Chuang FR. Low-molecular-weight heparin successfully treating a nephrotic patient complicated by renal and ovarian vein thrombosis and pulmonary embolism. Int J Clin Pract. 2005;59:72-5. doi: 10.1111/j.1368-504X.2005.00342.x.

8. Ricci MA, Lloyd DA. Renal venous thrombosis in infants and children. Arch Surg. 1990;125:1195-9. doi: 10.1001/ archsurg.1990.01410210121019.

9. Vasbinder GBC, Nelemans PJ, Kessels AG, Kroon AA, Maki 
JH, Leiner T, et al. Accuracy of computed tomographic angiography and magnetic resonance angiography for diagnosing renal artery stenosis. Ann Int Med. 2004;141: 674-82. doi: 10.7326/0003-4819-141-9-200411020-00007.

10. Kim HS, Fine DM, Atta MG. Catheter-directed thrombectomy and thrombolysis for acute renal vein thrombosis. J Vasc Interv Radiol. 2006;17:815-22. doi: 10.1097/01.RVI.0000209341.88873.26.

11. Ho KJ, Owens CD, Ledbetter SM, Chew DK, Belkin M.
Renal venous diversion: an unusual treatment for renal vein thrombosis. J Vasc Surg. 2006;43:1283-6. doi: 10.1016/j. jvs.2006.01.032.

12. Busi N, Capocasale E, Mazzoni MP, Benozzi L, Valle RD, Cambi V, et al .Spontaneous renal allograft rupture without acute rejection. Acta Biomed. 2004;75:131-3.

13. Zigman A, Yazbeck S, Emil S, Nguyen L. Renal vein thrombosis: a 10-year review. J Pediatr Surg. 2000;35:15402. doi: $10.1053 /$ jpsu.2000.18302.

Copyright (c) 2020 The Author(s); Published by Nickan Research Institute. This is an open-access article distributed under the terms of the Creative Commons Attribution License (http://creativecommons.org/licenses/by/4.0), which permits unrestricted use, distribution, and reproduction in any medium, provided the original work is properly cited. 